\title{
Does Growth Encourage Factor Price Equalization?
}

\author{
Alan V. Deardorff*
}

\begin{abstract}
This paper first notes the importance of "one-cone" versus "multi-cone" equilibria in the Heckscher-Ohlin model of international trade, then asks whether economic growth in neoclassical growth models leads toward one or the other. The one-cone equilibrium arises with internationally similar factor endowments. It has a single set (cone) of relative factor endowments, within which countries diversify and have global factor price equalization (FPE) under free trade. The multi-cone equilibrium arises with larger factor endowment differences. It has FPE within cones, but not between them. The two configurations differ in important ways. The paper examines several neoclassical trade-and-growth models, distinguished by their assumptions about saving, asking whether factor endowments converge into a single cone. None of the models suggests convergence, while some strongly imply that countries will end up in different cones. This suggests a preference for the multi-cone version of the model.
\end{abstract}

\section{Introduction}

The Heckscher-Ohlin (HO) model of international trade admits of two kinds of global free-trade equilibria. In one, factor prices are equalized across all countries, in the other they are not. The first equilibrium, with global factor price equalization (FPE), arises when factor endowments of countries are not too different from one another, in a manner that is sometimes described as being in the same "cone of diversification." The second equilibrium, without global FPE, arises when differences in factor endowments are greater. With many goods and countries, this second equilibrium has two or more groups of countries each with its own cone of diversification and FPE only among countries within the same cone. This is therefore sometimes called the "multi-cone" version of the $\mathrm{HO}$ model.

The differences between these two versions of the model can be important, for reasons that I will discuss further in section 2. Also, while most of the literature on the $\mathrm{HO}$ model, both theoretical and empirical, has focused on the one-cone version, there are reasons to think that the multi-cone version may be more relevant to the real world. This paper will explore theoretical reasons why one might expect this to be the case.

At any moment in time, what matters for global FPE is simply whether the factor endowments of the countries of the world are sufficiently similar, so as to lie in the same cone. ${ }^{1}$ However, over time factor "endowments" are not given, but evolve in response to the behavior of the countries themselves. Therefore, it is useful to ask whether the dynamics of economic growth tend to steer the countries of the world into the same cone, or into different ones. That is the issue I address in this paper.

In fact, at least one answer to this question is already present in the literature, and my main contribution is only to call attention to its importance for the nature of global

\footnotetext{
* Deardorff: University of Michigan, Ann Arbor, MI 48109, USA. Tel: 734-764-6817; Fax: 763-9181; E-mail: alandear@umich.edu. I have benefited from discussing the topic of this paper with Gordon Hanson, as well as from the comments of my discussant, Nan-Kuang Chen, and other participants in the Taiwan conference.
} 
equilibrium. In section 3, therefore, I recall a result from Stiglitz (1970), who noted that under one common formulation of rational saving, factor-price equalization becomes impossible in steady state for any two countries with different rates of time preference. This is not the only possible growth model, of course, and I will examine several alternative formulations that do not lead to this result. But the Stiglitz model is sufficiently important that it is worthwhile recognizing what it implies for the nature of global equilibrium in an $\mathrm{HO}$ world with many goods and countries.

This argument, then, adds theoretical reason for us to expect the world, if it conforms to the $\mathrm{HO}$ model at all, to fit more comfortably into its multi-cone specification. I take this as additional motivation for devoting future theoretical and empirical energy to exploring the properties of the multi-cone model and its fit with the data.

\section{One Cone, Two Cones,... .}

I will start by recalling some of the basic properties of the $\mathrm{HO}$ model, using the geometric framework of Deardorff (1974) since that will be convenient for my discussion of growth below.

Figure 1 shows the familiar properties of the two-good $\mathrm{HO}$ model, with factors capital $K$ and labor $L$. Given prices of two goods, $p_{1}$ of $X_{1}$ and $p_{2}$ of $X_{2}$, curves $\mathrm{OAZ}_{1}$ and $\mathrm{OBZ}_{2}$ indicate the per capita value at those prices of the output that could be produced in the respective sectors if they employed all of the economy's factors in the ratio $k=K / L$. That is, with linearly homogenous production functions $F_{i}\left(K_{i}, L_{i}\right)=L_{i} f_{i}\left(K_{i} / L_{i}\right)$, these curves show $p_{i} f_{i}\left(k_{i}\right)$. The convex hull of these two curves, $\mathrm{OABZ}_{2}$, formed by connecting them by their common tangent $\mathrm{AB}$, then measures the maximum value of per capita output that the country can produce by allocating its endowments to one or both of the two industries. It therefore also measures per capita income, $y$.

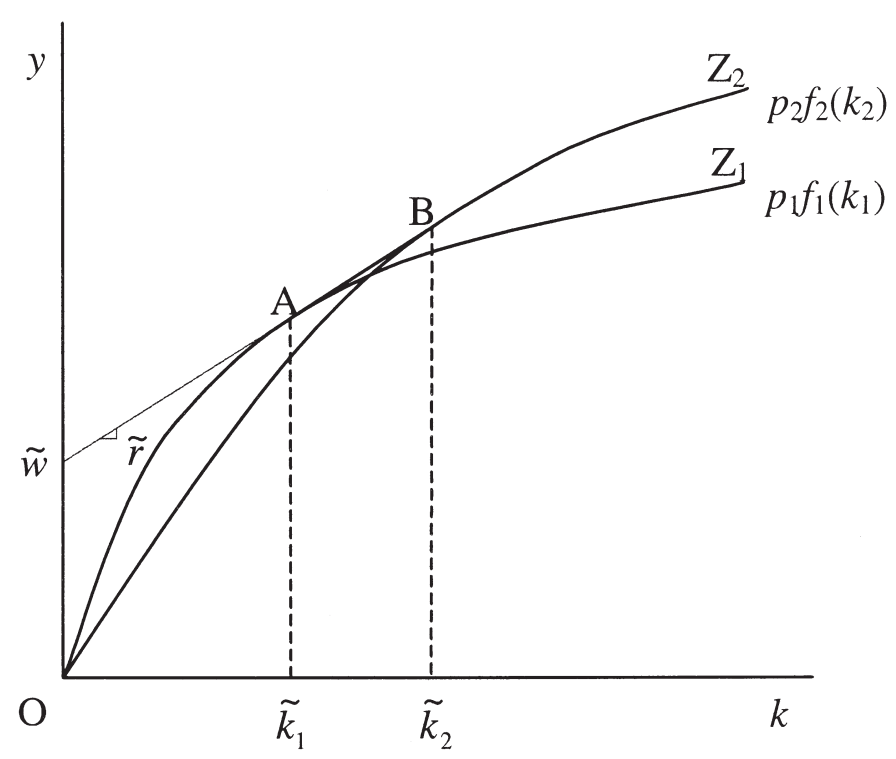

Figure 1. Two Goods, One Cone 
Only for endowment ratios between $\tilde{k}_{1}$ and $\tilde{k}_{2}$, below the tangencies, will the country produce both goods, and it will do so by employing the factors in these ratios within each industry, regardless of the capital-labor ratio of the country as a whole. This diagram is completely analogous to the more familiar Lerner diagram where these factor ratios are identified by a common tangent to the industries' unit-value isoquants, and where the corresponding rays from the origin in $(L, K)$ space form a cone. Thus in Figure 1 the interval between $\tilde{k}_{1}$ and $\tilde{k}_{2}$ can be thought of as the diversification cone, even though it does not look like a cone.

Other variables of the economy can also be read from this picture. As is familiar for linearly homogeneous production functions in intensive form, $f(k)$, the competitive return to capital, $r=f^{\prime}(k)$, is given by the slope of the curve, while the competitive wage, $w=f(k)-r k$, is given by the vertical intercept of the tangent to it. Both are of course constant throughout the cone of diversification, at the values shown as $\tilde{r}$ and $\tilde{w}_{.}^{2}$

Now suppose that there are more than two goods. I will consider only the threegood case, since that is enough to show the possibilities that arise with any number of goods. Adding a third good to Figure 1, there are two possibilities. For just the right price, the third good's value-of-per-capita production function will be exactly tangent to the common tangent $\mathrm{AB}$ or its extension. That is the one-cone case shown in Figure 2, where the common tangent is now $\mathrm{ABC}$, tangent to all three curves.

Alternatively, consider any other set of prices that are consistent with all goods being produced somewhere, under the usual HO assumption of identical technologies everywhere. ${ }^{3}$ Now there will be two common tangents, one touching the curves for the two most labor-intensive goods, and one touching the curves for the two most capitalintensive goods. This is the case in Figure 3. There, each common tangent defines a separate cone of diversification, indicating the range of factor endowment ratios for

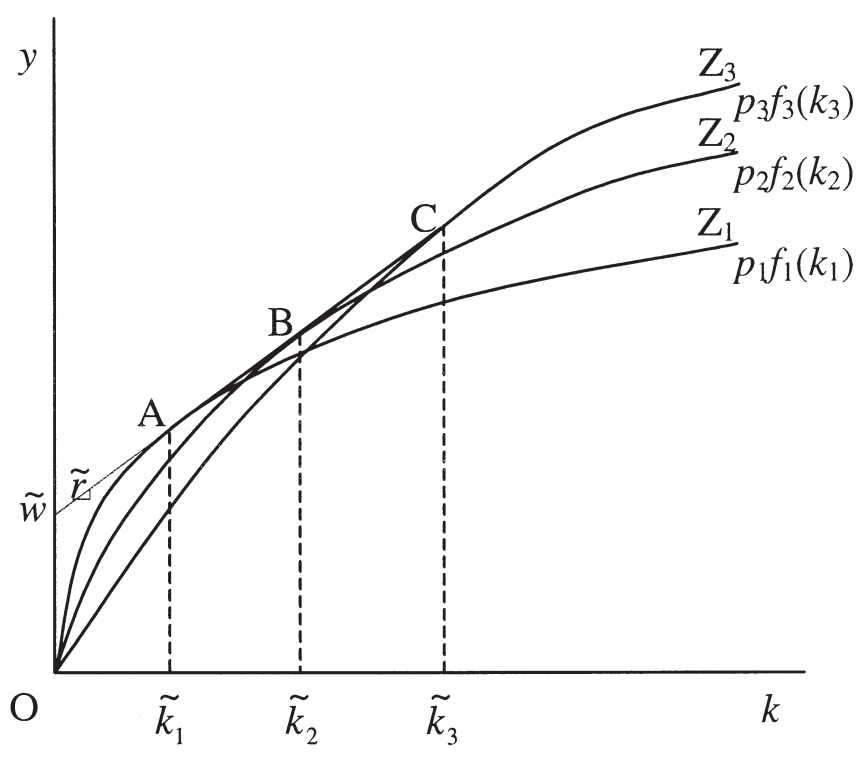

Figure 2. Three Goods, One Cone 


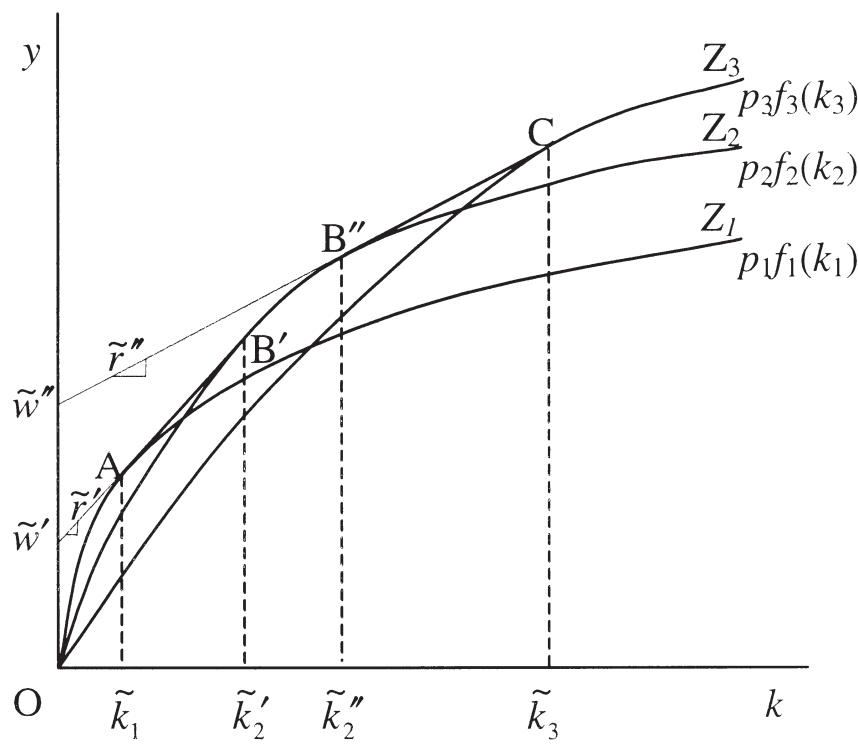

Figure 3. Three Goods, Two Cones

which its two respective goods can be produced within a single country. The two cones correspond not only to different goods being produced, but also to different factor prices, common to all countries within the cone but different from the other cone. There is also a space between the cones, from $\tilde{k}_{2}^{\prime}$ to $\tilde{k}_{2}^{\prime \prime}$, where only the good of intermediate factor intensity, $X_{2}$, is produced.

Much of international trade theory has dealt only with the two-goods case of Figure 1. Still more has allowed for more than two goods, but only in the one-cone case of Figure 2. This is evident not so much from the pictures that are drawn, since models with more goods than factors often avoid pictures, for obvious reasons. Rather, trade theorists routinely simply assume a world of global FPE, probably because of the simplicity that the assumption yields, so that they can get on with other issues. But as the marked differences between Figures 2 and 3 may suggest, the two models behave quite differently. Only recently have trade theorists begun to appreciate and explore these differences.

A good example is Davis (1996). He re-examines the Stolper-Samuelson theorem, one version of which is that trade liberalization will benefit a country's abundant factor. ${ }^{4}$ In a two-cone world, the logic of the proposition remains valid for trade liberalization affecting goods within a country's own cone, but only if factor abundance is defined relative to other countries within the cone, not relative to the world. Thus, for example, suppose in Figure 3 that there are several countries within the lower cone, and consider one whose endowment is near $\tilde{k}_{2}^{\prime}$. Since it is in the lower cone, it is laborabundant compared with the world. But it is capital-abundant compared with other countries in its cone, and therefore it will produce relatively little of the most laborintensive good, $X_{1}$. Since it therefore imports that good, a regime of protection will include a tariff on it, raising the domestic price $p_{1}$. This shifts the curve OAZ $Z_{1}$ upward (not shown), repositioning the common tangent with $\mathrm{OBZ}_{2}$, and raising the wage $\tilde{w}^{\prime}$. 
Reversing the process, then, this is a case in which removal of a tariff by a (globally) labor-abundant country lowers the wage.

There are many other such examples, but they tend to be less subtle than this one. Rather obviously, a tariff on the good that is not produced within a country's cone will not have the usual Stolper-Samuelson effects at all, but will only lower the real returns to both factors. This is not news, but it is a case that does not arise in the one-cone model except with complete specialization. Likewise, Rybczynski effects also do not occur for the good that is not produced, a fact that may somewhat diminish the tendency for growth through factor accumulation to worsen a country's terms of trade. But most important, and also most obvious, is simply the absence of FPE itself. In a multi-cone model, we can be sure that free trade does not equalize factor prices worldwide, and in fact it remains to be seen whether factor prices need even be brought closer together by trade. Factor prices are equalized within a cone, but that may provide little guidance to a country that does not know, prior to liberalization, into which cone it will fall, if either.

The failure of FPE, if it happens, ought to be of considerable interest for what it implies about worldwide wage inequality. But there is also another reason why it may be a cause for concern. If the world under free trade would have one cone and FPE among most countries, then as Mundell (1957) told us years ago, trade can substitute for factor mobility. To the extent that we see pressures for international movement of labor and capital, we can hope that those pressures will abate if barriers to trade are reduced. But if we are in a multi-cone world, that is not the case. Differences in wages and returns to capital will remain, even with perfectly free trade. The costs associated with migration of labor have long been evident. The costs associated with capital flows have become more clear recently with the crisis in Asia. In a multi-cone world these costs may be inevitable.

For all of these reasons, then, it is important to know whether the world, if it is $\mathrm{HO}$ at all, looks more like Figure 2 or Figure 3. An easy answer is available by just noting the large differences that exist across countries in factor prices, as well as the incentives for factor movement just mentioned. But while this evidence is tempting, it is not conclusive, since there are other reasons why factor prices may differ across countries without multiple cones. Within the framework of the HO model, transport costs and other trade barriers will do the job. ${ }^{5}$ And outside of $\mathrm{HO}$, or with a comparatively minor modification of it, there may be differences in technology across countries. ${ }^{6}$

This would seem to be an empirical question, then, ripe for the picking by the recent influx of empirical types into international trade that was documented in Leamer and Levinsohn (1995). Surprisingly, however, this work has without exception, I believe, assumed a one-cone world. Bowen et al. (1987), for example, base their analysis on Vanek's (1968) factor-content version of the HO theorem-the HOV theoremwhich assumes (unless technologies are Leontief) global FPE. One may perhaps interpret the poor performance of the theorem in their test as evidence for a multicone model, but without incorporating it into the analysis as an alternative hypothesis, as they do for several other explanations, there is no basis for confidence in such an interpretation.

There are, however, several empirical contributions that I find encouraging for the multi-cone view of the world. One is Davis et al. (1997), which I interpret as at least consistent with the multi-cone version of the model. Another is Debaere (1998), which, by departing from the constraints of $\mathrm{HOV}$, finds empirical support for relative 
factor endowments mattering for international trade. And most directly, Debaere and Demiroglu (1998) look empirically for satisfaction of the lens condition for global FPE ${ }^{7}$ both across the developed countries of the OECD and across a larger set of countries that include both less developed and newly industrializing countries. They find the condition to be satisfied for the developed OECD, but not for the larger group. Unfortunately, limitations of the data and the methodology leave open the possibility that the condition is satisfied for the larger group, but I nonetheless find their evidence to be highly suggestive.

The most recent and strongest empirical support for the multi-cone version has been from Davis and Weinstein (1998). Using a rich database that included both technology and absorption, as well as trade, from ten industrialized countries, they compared actual and predicted factor contents of production and trade. They used a sequence of assumptions permitting progressive relaxation of the stringent requirements of the HOV one-cone model. They found clear improvement in the empirical fit of the model when they allowed multiple cones of diversification.

What I conclude from this discussion, then, is that the multi-cone $\mathrm{HO}$ model is at least as plausible as the single-cone model for describing the world in which we live. However, regardless of which is the right model for today, there remains the possibility that this will change over time as countries grow. After all, the right model depends on whether the relative factor endowments of the countries of the world are sufficiently similar. And factor endowments themselves change over time as countries save and grow. Therefore, even if the world has one cone today (as I tend to doubt), it could have more than one tomorrow if relative factor endowments are diverging. Or if it has more than one cone today, it could have only one tomorrow, if they are converging. In the rest of the paper, I ask whether various models of economic growth give us a presumption one way or the other. To the extent that these models give an answer at all, it is to suggest that relative factor endowments are more likely to diverge over time than to converge. Therefore, even if we live in one cone today, it is unlikely that we will stay there.

The question here is similar to the issue of "convergence," that has occupied so much of recent growth literature. Starting with Baumol (1986) and continuing through contributions of Barro and Sala-i-Martin (1992), Mankiw et al. (1992), and others nicely summarized by Mankiw (1995), macroeconomists have asked whether countries are becoming more alike in terms of their levels of productivity and per capita incomes. They have also asked whether that convergence, if it occurs, is unconditional, conditional on identical behavioral parameters, or present only within groups of countries with similar initial conditions (convergence clubs). The approach has been mostly empirical, its theoretical foundation being primarily the Solow closed-economy growth model. Of course, per capita incomes and factor prices are related to one another, and the models I will look at here also have implications for the convergence literature, some of which I have explored in Deardorff (1997).

\section{Can Growth Paths Stay in One Cone?}

I will confine my attention to neoclassical growth models. I do that primarily because that is the landscape with which I am most familiar. But it is also the place where the question I am asking makes most sense and is most difficult to answer. As I noted in Deardorff (1999), the mechanisms of endogenous growth tend to make it possible for 


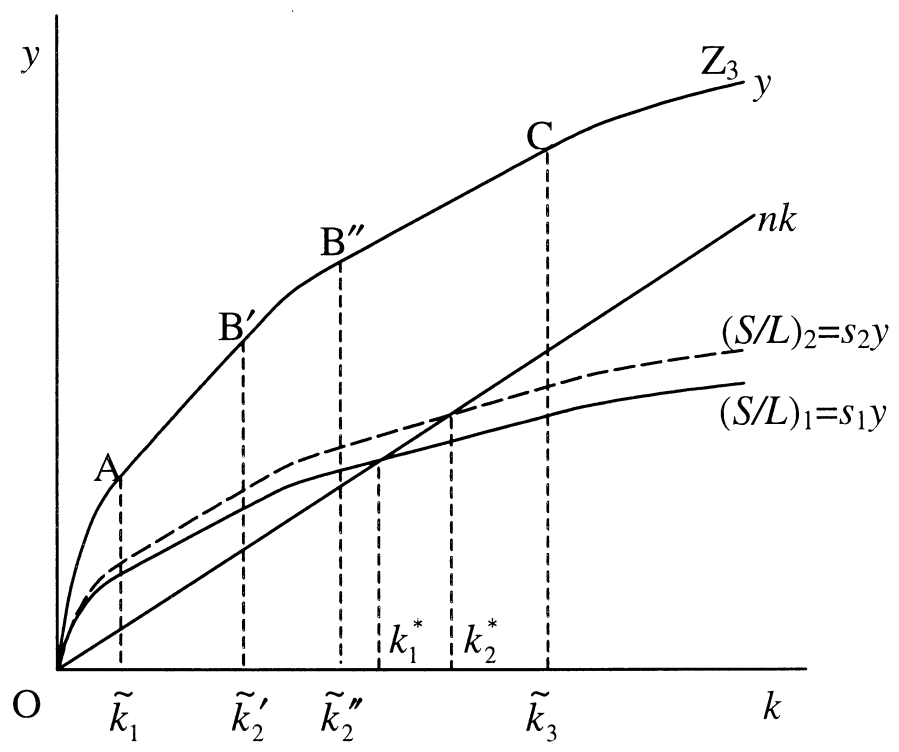

Figure 4. Growth with Proportional Savings

countries to grow at different rates indefinitely. If that happens, it almost inevitably means that the faster growing countries are accumulating something in ever-greater amounts relative to their slower growing neighbors. What they accumulate may or may not be capital, but it is hard to imagine anything like an HO model in such a context that would be able to accommodate these ever more diverse countries within a single cone.

Neoclassical growth models, on the other hand, tend to have steady states in which the capital-labor ratios of countries are constant, and these could then easily lie within a single cone. For example, the seminal trade and growth model of Oniki and Uzawa (1965) followed Solow (1956) in assuming that savings were simply proportional to income. In such a model, even with international trade, the steady-state capital-labor ratio varies smoothly with the savings propensity. This can be seen easily in Figure 4, which illustrates growth with proportional savings for the two-cone case, although the conclusion clearly holds more generally. Let the prices be those of the ultimate world steady state. Then the growth of any country that is small enough to take those prices as given, and that also arrives late enough in the growth process to take them as constant, can be illustrated exactly as in the Solow model. The convex hull, $\mathrm{OAB}^{\prime} \mathrm{B}^{\prime \prime} \mathrm{CZ}_{3}$ from Figure 3 is reproduced, indicating the value of the country's per capita national income, $y$. With a constant fraction, $s_{1}$, of that income saved, per capita saving and thus per capita investment is a curve just like the convex hull, but shrunken vertically downward. Following the usual dynamics of the Solow model (and neglecting depreciation), the time derivative of the capital-labor ratio, $k$, is given by:

$$
\dot{k}=I / L-n k,
$$

where $I$ is investment and $n$ is the population growth rate. Equating saving and investment, ${ }^{8}$ the steady state is therefore the intersection of this scaled-down convex hull with the ray, $n k: k_{1}^{*}$. 


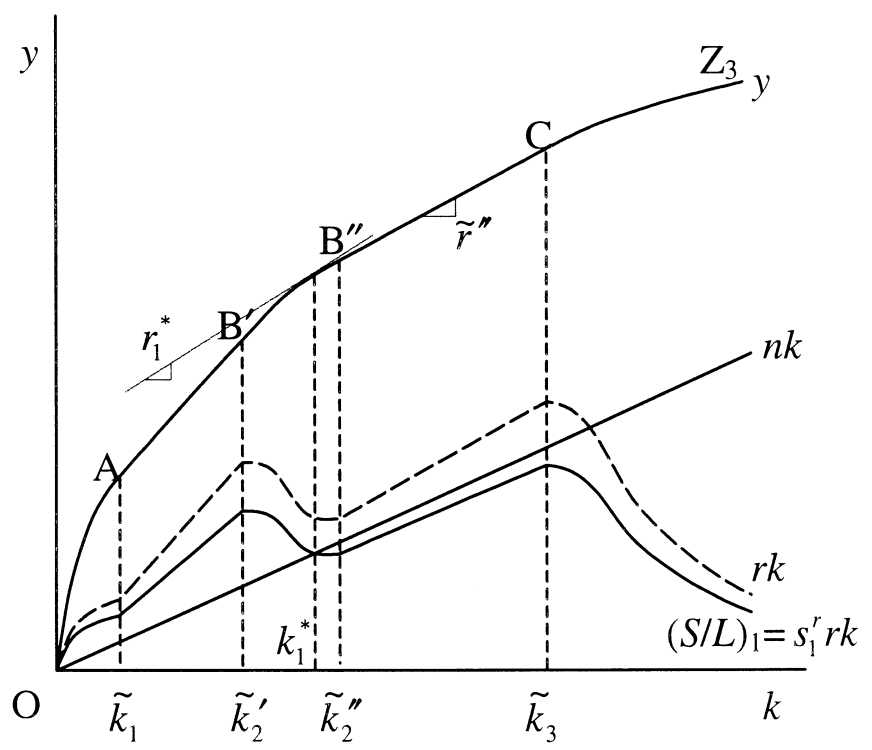

Figure 5. Growth with Classical Savings

From this it is evident that a slightly higher propensity to save, such as $s_{2}$ in Figure 4 , will lead to only a slightly larger steady-state capital-labor ratio, $k_{2}^{*}$. It is therefore easy enough to get two countries with different savings propensities to have steady states in the same cone, as shown. In general, then, with proportional saving, whether the world arranges itself into one cone or more than one depends simply on how diverse are the countries' savings propensities. If they differ significantly across countries, then so will their capital-labor ratios in steady-state growth, and a single cone with worldwide FPE will not be sustainable. If saving propensities are similar, however, a one-cone world may be the natural outcome.

A different outcome is possible, however, if saving is not a simple fixed proportion of income. Early growth models often took as an alternative to proportional saving the assumption that saving came only out of profits. This was sometimes called "classical (or Marxian) saving." Figure 5 shows the quite different behavior that arises in this case, again for the two-cone scenario. Since the rate of return to capital is given by the slope of the per capita income curve, $y$, total per capita profit, $r k$, within either of the cones where $r$ is constant, is just a ray from the origin parallel to the $y$ curve itself. Outside the cones, $r k$ can either rise or fall (since $k$ rises while $r$ falls), but it must cross such rays from above. Thus per capita profit looks something like the dashed curve labeled $r k$ in Figure 5. With a constant fraction, $s_{1}^{r}$, of profits saved, per capita savings looks just like this but, again, scaled down by the savings parameter, as shown.

The distinctive property of this curve is that, because it too coincides with rays from the origin inside each cone, it cannot cross the $n k$ ray within a cone. It could, by happenstance, coincide with that ray throughout a cone, but it cannot cross it. Therefore, except in such coincidences, steady states with classical savings will lie between cones, not within them. Even when such coincidences do occur, the entire cone will be a 
steady state, and the dynamics of growth, if prices are constant, will lead only to the edge of a cone, not inside it. Therefore, with classical saving we do not expect to find countries inside of cones in the long run.

Now neither of the cases in Figures 4 and 5 are generally regarded as theoretically acceptable growth models, even by the standards of economic analysis of the late 1960s, when much of this work was being done. The reason is that these savings assumptions do not follow from any model of rational behavior, or optimization, by consumers.

The first to correct this in an international trade context was Stiglitz (1970). He assumed a representative, infinitely lived consumer with a constant rate of time preference, and he solved for the steady state of a trading country whose growth is determined by the saving of such a consumer. What he found, quite simply, was that such a country will continue to accumulate capital relative to labor as long as the rate of return to capital exceeds the rate of time preference, and it will allow the capital-labor ratio to decline whenever the opposite is true.

This is not in general equivalent to either of the saving behaviors analyzed above, but the implications for steady-state growth are the same as the classical savings case. A Stiglitz economy with rate of time preference equal to, say, $r_{1}^{*}$ in Figure 5 will, like the classical economy, have per capita saving above $n k$ for all $k$ below $k_{1}^{*}$ and per capita saving below $n k$ for all $k$ above this. Likewise, if the rate of time preference happened to equal the return to capital in one of the cones, say $\tilde{r}^{\prime \prime}$, then throughout that cone the economy would save neither more nor less than needed to hold $k$ constant, and the entire cone would be a steady state.

Thus, Stiglitz provided a particular formulation of optimal savings that led to the conclusion that an economy would completely specialize. This same conclusion has been revived by Baxter (1992), who noted the similarity of the model in steady state to the static Ricardian model. In a world of many goods and countries, complete specialization in a single good is not as likely, although the parallel with the Ricardian model still holds. If every country has a different rate of time preference, then each will be the sole occupant, in steady state, of the portion of the per capita income curve with slope equal to that rate of time preference. ${ }^{9}$ For some countries, this may indeed mean producing only one good. For others, especially ones that are large (in terms of labor), it may mean having their own cone of diversification all to themselves, each being the only country to produce in the interior of its respective cone.

Rational saving, then, like classical saving, seems very unlikely to lead to a one-cone $\mathrm{HO}$ world. Only if all countries shared the same rate of time preference would a single cone accommodate them all. Some diversity of time preference for a few countries would be possible with a single cone in steady state, but this would require that the outliers in terms of time preference also be outliers in terms of what they produce. They would each have to specialize completely in either the single most capitalintensive or the single least capital-intensive good. With many goods, this configuration becomes implausible.

It may seem, therefore, that the Stiglitz model should be the last word on this subject: if saving is rational, then a one-cone world is unlikely. Unfortunately, although the Stiglitz model does rest on consumer optimization, the consumer who performs that optimization is of a rather special sort. Consumers live forever and, more importantly in my view, their rate of time preference, being constant, is independent of their consumption path. In the world of economic theory, these restrictions may seem minor, 


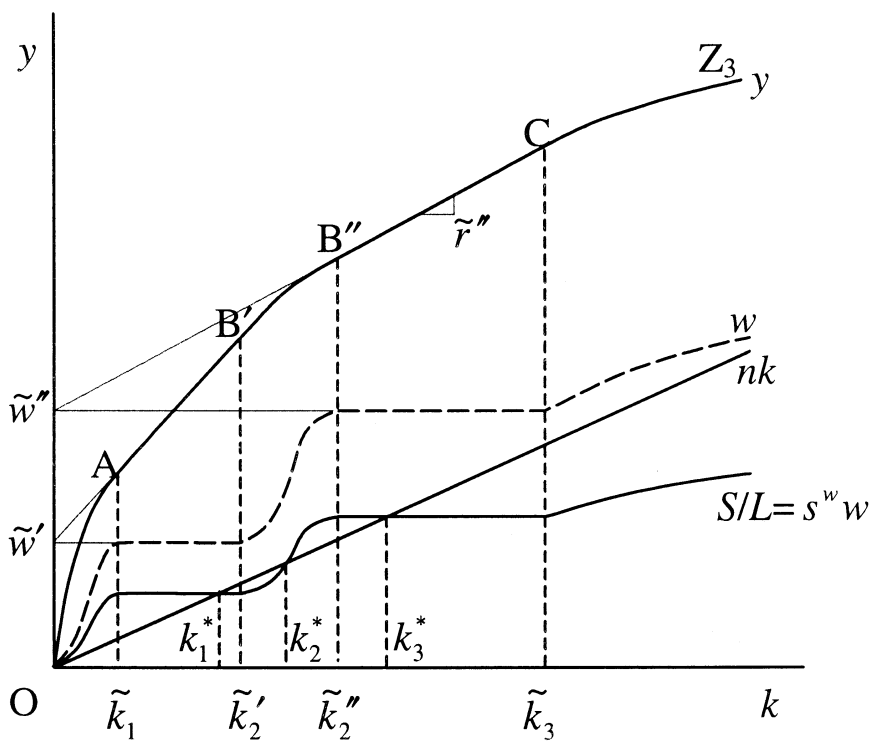

Figure 6. Growth with Savings from Wages

but for the conclusion here they seem to be critical. Therefore it may be worth looking for manageable alternatives.

One such alternative is provided by Galor $(1992,1996)$, who has reformulated the neoclassical growth model assuming a simple two-period overlapping-generations (OLG) economy. His consumers save just as rationally as those of Stiglitz, but for a much shorter time. And their behavior is therefore quite different. Under the usual assumptions of the simplest OLG model, consumers work only in the first period and retire in the second. Without bequests, it is only first-period consumers who will save, since only they have a future. And their saving in that first period can come only out of wages, since that is their only source of income. The portion of their wages that they choose to save can still depend on the rate of return to capital, but it need not necessarily do so since the usual income and substitution effects of the rate of interest on savings pull in opposite directions. If, for example, the utility function on current and future consumption is Cobb-Douglas, then these two forces balance out and the fraction of (wage) income saved is constant.

This, as I have explored elsewhere in Deardorff (1997), leads to quite different growth performance than any of the models looked at so far. Figure 6 illustrates, again for the two-cone case. Recall that the wage is given by the vertical intercept of the tangent to the per capita income curve, and that this is constant inside any cone. Then the per capita wage bill (which is the wage rate) can easily be derived as the curve labeled $w$. Letting a fraction $s^{w}$ of this be saved gives the per capita saving curve shown. It is horizontal within each cone, and unlike saving out of profits in the classical case, easily gives rise to steady states within cones.

Too easily, one might say. For if there do exist multiple cones as in the case shown, then it is not hard to get multiple steady states as well. This is the main point made in Deardorff (1997). In the case shown in Figure 6, there are three steady states, where 
$S / L$ crosses $n k$ at $k_{1}^{*}, k_{2}^{*}$, and $k_{3}^{*}$. Of these, the middle steady state is dynamically unstable, and the stable steady states both happen to occur within cones. The implication is that two countries with identical behavior but with different initial conditions may end up in quite different steady states, including different factor prices, different per capita incomes, and different patterns of specialization and trade.

For the purpose here, however, of determining implications for the number of cones, this is not definitive. Unlike the cases of classical saving and Stiglitz's formulation of rational saving, this one (which can also be rational, in this particular OLG context) does easily permit countries to diversify in steady state. I have not drawn the picture for this case, but the reader can easily add the requisite curves to, say, Figure 2 and verify that countries can continue to occupy the single cone in steady state, even with a variety of saving propensities out of wages. Thus Galor's OLG model does not imply that a single-cone world is unlikely. If countries "start" with factor endowments sufficiently close together to yield global FPE in the static model, then there is no reason in the growth model why this state of affairs cannot continue.

What the model does suggest, however, is that if countries start in multiple cones, then that too is likely to continue. Therefore there is nothing in Galor's growth model to predispose the world toward either situation.

\section{Conclusion}

To conclude, then, there seems to be nothing in the available neoclassical growth models to suggest that the growth process is likely to bring the countries of the world sufficiently close together in terms of their factor endowments to permit global FPE. Furthermore, there do exist respectable models that suggest rather contrary conclusions. If countries differ at all in their rates of time preference in the Stiglitz model (or in the fractions of their profits that they save in the classical model), then they will not be able to occupy the same cone of diversification. Multiple cones are then inevitable. Alternatively, in other models where saving comes out of wages, a different sort of anomaly arises. There, if countries happen to start the growth process with such diverse factor endowments that multiple cones arise in the short run, then these multiple cones can lead to corresponding multiple steady states, so that the multiple cones continue to exist even in the long run.

\section{References}

Barro, Robert and Xavier Sala-i-Martin, "Convergence," Journal of Political Economy 100 (1992):223-51.

Baumol, William J., "Productivity Growth, Convergence, and Welfare: What the Long-Run Data Show," American Economic Review 76 (1986):1072-85.

Baxter, Marianne, "Fiscal Policy, Specialization, and Trade in the Two-Sector Model: The Return of Ricardo?" Journal of Political Economy 100 (1992):713-44.

Bowen, Harry P., Edward E. Leamer, and Leo Sveikauskas, "Multicountry, Multifactor Tests of the Factor Abundance Theory," American Economic Review 77 (1987):599-620.

Davis, Donald R., "Trade Liberalization and Income Distribution," manuscript (1996).

Davis, Donald R. and David E. Weinstein, "An Account of Global Factor Trade," Discussion Paper 435, Research Seminar in International Economics, University of Michigan, 16 October (1998). 
Davis, Donald R., David E. Weinstein, Scott C. Bradford, and Kazushige Shimpo, "Using International and Japanese Regional Data to Determine When the Factor Abundance Theory of Trade Works," American Economic Review 87 (1997):421-46.

Deardorff, Alan V., "A Geometry of Growth and Trade," Canadian Journal of Economics 7 (1974):295-306.

-, "Overview of the Stolper-Samuelson Theorem," in Alan V. Deardorff and Robert M. Stern (eds.) The Stolper-Samuelson Theorem: A Golden Jubilee, Ann Arbor, MI: University of Michigan Press (1994a):7-34.

- "The Possibility of Factor Price Equalization, Revisited," Journal of International Economics 36 (1994b):167-75.

- "Rich and Poor Countries in Neoclassical Trade and Growth," Discussion Paper 402, Research Seminar in International Economics, University of Michigan, 29 June (1997).

— , "Diverging Populations and Endogenous Growth in a Model of Meaningless Trade" Review of International Economics 7 (1999):365-88.

Debaere, Peter, "Endowments Do Matter: Relative Factor Abundance and Trade," ch. 3 in The Factor Proportions Theory of International Trade and Finance, $\mathrm{PhD}$ thesis, University of Michigan (1998).

Debaere, Peter with Ufuk Demiroglu, "On the Similarity of Country Endowments and Factor Price Equalization," ch. 2 in The Factor Proportions Theory of International Trade and Finance, PhD thesis, University of Michigan (1998).

Demiroglu, Ufuk and Kwan Koo Yun, "The Lens Condition for Factor Price Equalization," Journal of International Economics 47 (1999):449-56.

Galor, Oded, "A Two-Sector Overlapping-Generations Model: A Global Characterization of the Dynamical System,” Econometrica 60 (1992):1351-86.

- "Convergence? Inferences from Theoretical Models," Economic Journal 106 (1996):1056-69.

Leamer, Edward E. and James Levinsohn, "International Trade Theory: The Evidence," in Grossman and Rogoff (eds.), Handbook of International Economics, Vol. III, Amsterdam: North-Holland (1995).

Mankiw, N. Gregory, “The Growth of Nations," Brookings Papers on Economic Activity 1 (1995): 275-310.

Mankiw, N. Gregory, David Romer, and David N. Weil, "A Contribution to the Empirics of Economic Growth," Quarterly Journal of Economics 107 (1992):407-37.

Mundell, Robert A., "International Trade and Factor Mobility," American Economic Review 47 (1957):321-35.

Oniki, H. and H. Uzawa, "Patterns of Trade and Investment in a Dynamic Model of International Trade," Review of Economic Studies 32 (1965):15-38.

Solow, Robert, "A Contribution to the Theory of Economic Growth," Quarterly Journal of Economics 70 (1956):65-94.

Stiglitz, Joseph E., "Factor Price Equalization in a Dynamic Economy," Journal of Political Economy 78 (1970):456-88.

Trefler, Daniel, "International Factor Price Differences: Leontief Was Right," Journal of Political Economy 101 (1993):961-87.

- "The Case of the Missing Trade and Other Mysteries," American Economic Review 85 (1995):1029-46.

Vanek, Jaroslav, "The Factor Proportions Theory: The $n$-Factor Case," Kyklos 4 (1968):74956.

Xiang, Chong, "The Sufficiency of the 'Lens Condition' for Factor Price Equalization in the Case of Two Factors," Discussion Paper 434, Research Seminar in International Economics, University of Michigan, 11 January (1999). 


\section{Notes}

1. Actually, with many goods and countries, it is not exactly cones that matter, but lenses, as in Deardorff (1994b). The cone terminology is sufficiently well established, however, that I will use it.

2. As discussed in Deardorff (1974), much like the Lerner diagram, this one also readily yields the main theorems of the HO model. The FPE theorem is just the stated constancy of these two factor prices within the cone. The Stolper-Samuelson Theorem is easily found by varying one of the prices and thus expanding or contracting one of the industry curves vertically and adjusting the common tangent. Per capita outputs of the two goods are given within the cone by the straight-line diagonals of the trapezoid $\tilde{k}_{1} \mathrm{AB} \tilde{k}_{2}$. From those diagonals, the Rybczynski and Heckscher-Ohlin theorems follow easily.

3. For example, given $p_{1}$ and $p_{3}$ in Figure 2, any lower price for $p_{2}$ would not permit good 2 to be produced anywhere, since producers could always earn greater revenue by producing a mix of goods 1 and 3 .

4. For others, see Deardorff (1994a).

5. One may doubt that trade barriers in today's world are large enough to account for the differences in factor prices, especially wages, that we see. On the other hand, nontariff barriers are widely presumed to exist well beyond our ability to measure them.

6. See Trefler $(1993,1995)$.

7. The lens condition, derived in Deardorff (1994b), is the appropriate generalization to many goods, factors, and countries of $2 \times 2 \times 2$ requirement that countries be in the same cone. It is necessary for global FPE but not in general sufficient, as shown by Demiroglu and Yun (1999). It is, however, sufficient for FPE in the two-factor case of their analysis, as shown by Xiang (1999).

8. I assume that there are no international capital flows, so that a country must rely on its own saving in order to grow. It is also necessary for this construction in the figure that the numerraire for prices be whatever good or goods are needed for investment. Since I will not be changing prices, that is not a problem.

9. Of course, this curve depends on prices, which must adjust as usual to equate supply and demand. What I am describing is only a property of the equilibrium, not its full characterization. 